\title{
An Enantioselective Cascade Cyclopropanation Reaction Catalyzed by Rhodium(I): Asymmetric Synthesis of Vinylcyclopropanes
}

\author{
Òscar Torres, ${ }^{\mathrm{a}}$ Anna Roglans, ${ }^{\mathrm{a}}$ and Anna Pla-Quintana ${ }^{\mathrm{a}, *}$ \\ a Institut de Química Computacional i Catàlisi (IQCC) and Departament de Química, Universitat de Girona (UdG), \\ Facultat de Ciències, C/ Maria Aurèlia Campmany 69, 17003 Girona, Spain \\ Fax: (+34)-972-418-150; phone: (+34)-972-418-275; e-mail: anna.plaq@udg.edu
}

Received: July 21, 2016; Revised: September 7, 2016; Published online: $\mathbf{\square}$ u, 0000

Supporting information for this article can be found under: http://dx.doi.org/10.1002/adsc.201600789.

\begin{abstract}
N$-Tosylhydrazone-yne-ene substrates are satisfactorily prepared and their cyclization under rhodium catalysis is evaluated. A cascade process involving rhodium vinyl carbene formation through carbene/alkyne metathesis - and cyclopropanation has been developed to stereoselectively afford vinylcyclopropanes.
\end{abstract}

Keywords: carbenes; cyclization; cyclopropanes; enantioselectivity; rhodium

The construction of polycyclic structures with proper stereochemical control is a major challenge in organic synthesis. Among these structures, small ring-containing compounds - cyclopropane and cyclopropane-containing polycyclic derivatives - have attracted considerable interest due to their presence in bioactive substances. ${ }^{[1]}$ This is the case of bicyclo[3.1.0] derivatives (Figure 1), which are found at the core of Eglumegad,

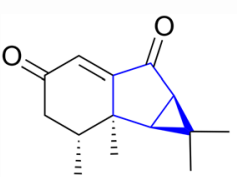

(-)-Nardoaristolone B

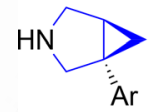

Bicifadine, $\mathrm{Ar}=4-\mathrm{MeC}_{6} \mathrm{H}_{4}$ DOV21947, $\mathrm{Ar}=3,4-\mathrm{Cl}_{2} \mathrm{C}_{6} \mathrm{H}_{3}$

Figure 1. Examples of compounds containing a bicyclo[3.1.0]hexane ring system. effective for treating anxiety symptoms and in relieving the symptoms of withdrawal from chronic use of drugs,${ }^{[2]}$ and also of bicifadine and DOV21947, which are being studied for the treatment of chronic pain and depression, respectively. ${ }^{[3]}$ (-)-Nardoaristolone B, which exhibits protective activity on the injury of neonatal rat cardiomyocytes, ${ }^{[4]}$ and (+)-Sarcandralactone $\mathrm{A},{ }^{[5]}$ a vinylcyclopropane derivative, constitute further examples of compounds containing this moiety at the core.

Cyclopropane-containing compounds are also recognized for their rich reactivity that, either through ring-opening or rearrangement, allow for the synthesis of a multitude of topologically different compounds. ${ }^{[6]}$ The synthetic applications of cyclopropanecontaining compounds are enhanced when the derivatives bear activating groups that can facilitate their ring opening or offer opportunities for futher transformations, as occurs in the case of vinylcyclopropanes (VCP). ${ }^{[7]}$

The asymmetric cyclopropanation of olefins stands out as one of the most versatile and straightforward methods for the stereoselective synthesis of cyclopropanes, ${ }^{[8]}$ and metal carbenes ${ }^{[9]}$ are among the most efficient cyclopropanating agents. When metal vinyl carbenes are used for this purpose, vinylcyclopropanes can be obtained directly (Scheme 1). There are several examples in which the decomposition of vinyl diazo compounds has been used as a source of vinyl carbenes, which make enantioselective cyclopropanation reactions possible (Scheme 1, a) $\cdot{ }^{[10]}$ However, an electron-withdrawing group adjacent to the diazo funcionality is necessary to facilitate its synthesis, inhibit side reactions and achieve high stereoselectivity.

Another strategy is the use of transition metal-catalyzed ring-opening of cyclopropenes to afford transition metal vinyl carbenes under mild conditions due to their intrinsic ring strain (Scheme 1, b). ${ }^{[11]}$ When properly substituted cyclopropenes are reacted, regio- 
a) Vinyl diazo compound decomposition:<smiles></smiles><smiles>[R16]C(=[W])C([R])=C([R])[R]</smiles><smiles>C[As]=[W]</smiles><smiles>[R]C([R])=C([R])C1(C(C)(C)C)CC1[R]</smiles>

b) Cyclopropene ring-opening:

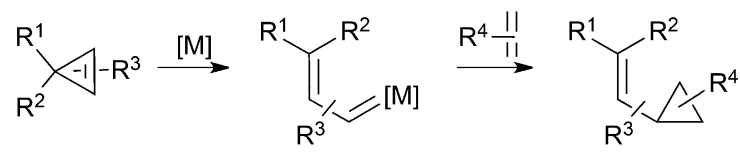

c) Rearrangement of propargylic esters:<smiles>[R]C#CC([R1])(C#C[R1])OC([R])=O</smiles>

d) Carbene/alkyne metathesis:<smiles>[R]C#C[R]</smiles>

Scheme 1. Strategies for the synthesis of VCPs by alkene cyclopropanation with metal vinyl carbenes.

selective ring-opening takes place but no enantioselective cyclopropanation has been achieved so far.

The transition metal-catalyzed rearrangement of propargylic esters, providing access to metal vinyl carbenes when a 5-exo-dig cyclization takes place (also referred to as 1,2-shift), has also been explored (Scheme 1, c). ${ }^{[12]}$ Remarkably, Toste et al. reported the enantioselective synthesis of vinylcyclopropanes using a gold vinyl carbene generated by transition metal-induced rearrangement of a propargyl ester that either intra- or intermolecularly reacted with an alkene. ${ }^{[13]}$

Finally, metal vinyl carbenes have also been obtained through carbene/alkyne metathesis, a process by which a transition metal carbene reacts with an alkyne, transferring the carbene-like character to the $\beta$-carbon of the alkyne, ${ }^{[14]}$ and then reacted with alkenes to obtain vinylcyclopropanes (Scheme 1, d). ${ }^{[15]}$ When the carbene/alkyne metathesis-cyclopropanation cascade takes place intramolecularly, polycyclic compounds can be obtained but none of the cases reported so far $^{[16]}$ involves enantioselective cyclopropanation.

We have recently described an enantioselective synthesis of sulfones through a cascade triggered by a base-free decomposition of $N$-sulfonylhydrazones featuring a two-fold carbene/alkyne metathesis. ${ }^{[17]} \mathrm{N}$ Tosylhydrazones are used as an efficient in situ source of non-stabilized diazo compounds. ${ }^{[18]}$ Having developed a methodology to use the chiral catalyst to mediate carbene/alkyne metathesis, we decided to test whether chiral vinylcyclopropanes could be obtained by the reaction of an enyne tethered to an $N$-tosylhydrazone. In this communication we report the realization of this goal.

We initially studied the cyclization of substrate $\mathbf{1 a}^{[19]}$ under the conditions that triggered cyclization in our previous study (Scheme 2). Using dichloroethane

$\left[\mathrm{Rh}(\mathrm{cod})_{2}\right] \mathrm{BF}_{4}(10 \mathrm{~mol} \%)$

(S)-BINAP (10 mol\%)
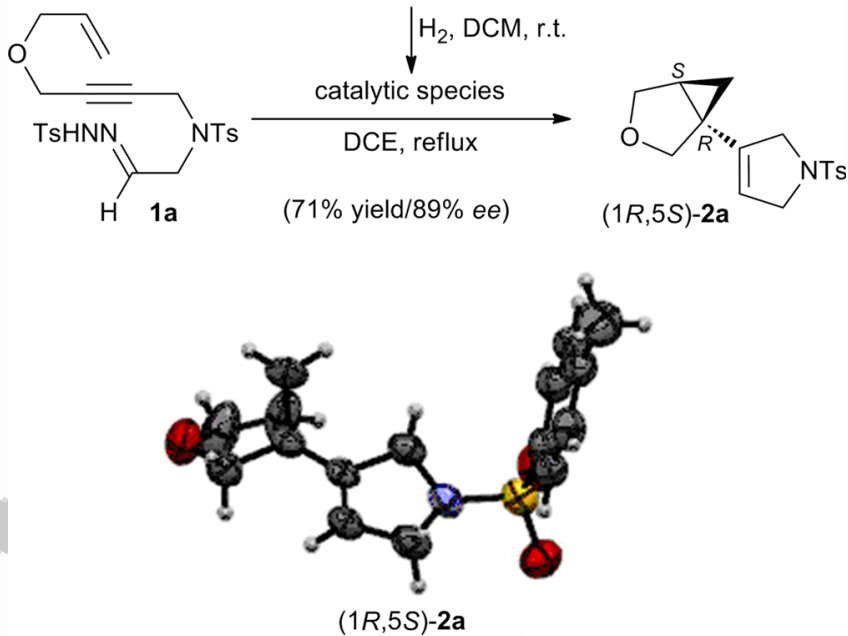

Scheme 2. Investigation of the reactivity. (ee value corrected).

as the solvent at reflux, the reaction worked efficiently to afford a $71 \%$ yield of vinylcyclopropane $(1 R, 5 S)$-2a with a $78 \%$ enantiomeric excess. It is remarkable that the reaction works without the need to add a base for $N$-tosylhydrazone activation. After some effort, single crystals of the cycloadduct were obtained from which the solid phase structure was solved and the absolute configurations of the stereocentres were determined. ${ }^{[20]}$ When the atropoisomeric ligand of the rhodium was changed to $(R)$-BINAP, a $55 \%$ yield of $(1 S, 5 R)-\mathbf{2 a}$ was isolated with an $89 \%$ enantiomeric excess.

The reaction was then extended to substrates $\mathbf{1 b}$ $\mathbf{f}^{[19]}$ which differ in the units tethering their reactive moieties (Table 1).

Substrates containing sulfonamide tethers in both $\mathrm{X}$ and $\mathrm{Z}$ positions (2b-d, Table 1$)$ were successfully reacted under the cyclization reaction conditions giving the cycloadducts in good yields. Whereas the vinylcyclopropanes containing NTs tethers could be efficiently characterized, the low solubility of both the 4-nitrobenzenesulfonyl (Ns) and 2-nitrobenzenesulfonyl (2Ns) tethers prevented the determination of the enantiomeric excess of the products obtained. A malonate 
Table 1. Scope and limitations of the process. ${ }^{[a]}$

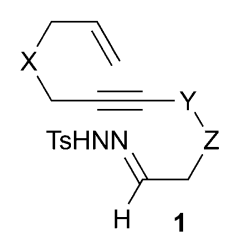

$\left[\mathrm{Rh}(\mathrm{cod})_{2}\right] \mathrm{BF}_{4}(10 \mathrm{~mol} \%)$

(S)-BINAP (10 mol\%)

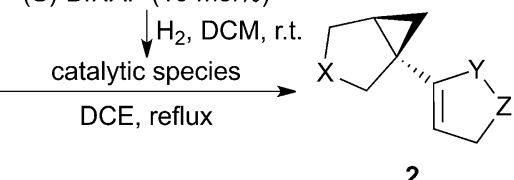

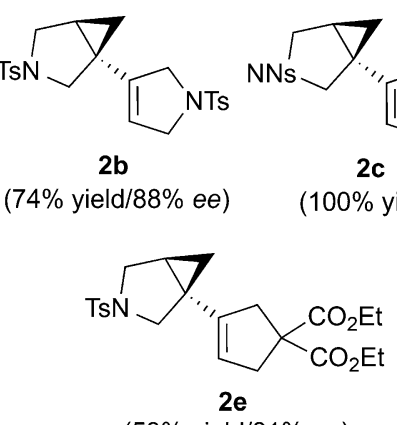

$(53 \%$ yield $/ 81 \%$ ee $)$

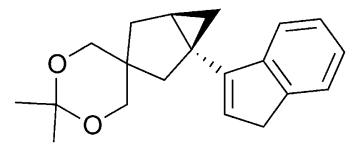

$2 \mathrm{~g}$

$(21 \% \text { yield })^{[b]}$

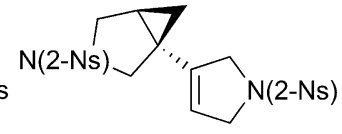

2d

$(71 \% \text { yield })^{[b]}$

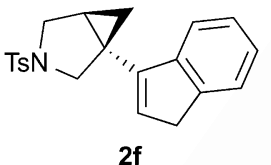

$(67 \%$ yield $/ 82 \%$ ee $)$

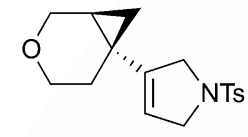

$2 \mathrm{~h}$

(n.r.) [a] The reaction was performed with $0.10 \mathrm{mmol}$ of substrate 1 in dichloroethane $(1.5 \mathrm{~mL}, 0.067 \mathrm{M})$. The mixture of $\left[\mathrm{Rh}(\operatorname{cod})_{2}\right] \mathrm{BF}_{4}$ and $(S)$-BINAP was treated with hydrogen in DCM solution for catalyst activation prior to the reaction.

[b] The enantiomeric excess could not be determined due to the low solubility and absorptivity.

tether was also introduced between the hydrazone and the alkyne and the cyclized product $2 \mathbf{e}$ was obtained with moderate yield but high $e e$. By the reaction of substrates that feature a phenyl ring between the alkyne and the toluenesulfonylhydrazone, indenyl-substituted bicyclo[3.1.0] derivatives were also available. The cyclized product $\mathbf{2 f}$ was efficiently obtained when an NTs tether was placed in the enyne moiety. When this moiety was linked through a cyclic acetal (2,2-dimethyl-1,3-dioxane), the reaction to provide product $\mathbf{2 g}$ was only moderately efficient. Finally, and as has been found in other studies, ${ }^{[21]}$ no reaction was observed when the tether length of the enyne moiety was increased (2h). The absolute stereochemistry of each of the products shown in Table 1 was assigned by analogy with product $\mathbf{2 a}$.

The substituents on the alkene group markedly affect the outcome of the carbene/alkyne metathesiscyclopropanation sequence. When substrates $\mathbf{3}$, which feature a trans-1,2-disubstituted alkene, were subjected to the reaction conditions, the efficiency of the reaction drastically dropped and only low quantities (4a) or traces (4b) of the corresponding vinylcyclopropanes were detected by NMR in the crude reaction

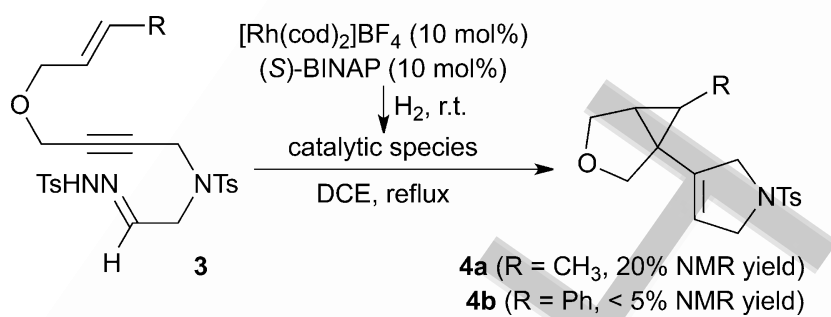

Scheme 3. Reactions of 1,2-disubstituted olefins.

mixture that contained a considerable amount of unidentified by-products (Scheme 3).

The reactivity of substrate $\mathbf{5}$, which has a 1,1-disubstituted alkene, was then evaluated (Table 2). Only a $29 \%$ yield of vinylcyclopropane 6 was isolated under the reaction conditions used for the unsubstituted alkenes, although with good enantioselectivity (entry 1, Table 2). Since the reaction in this case was quite clean, we decided to optimize the reaction conditions. To begin with, the effect of an added base was evaluated (entry 2, Table 2) but on adding three equivalents of potassium carbonate to the reaction mixture only traces of the cyclized compound were formed. The reaction solvent was then switched to 1,2-dichloropropane (1,2-DCP) to increase the temperature but this resulted in a decrease in both the yield and the enantioselectivity (entry 3 , Table 2).

In these reactions, the catalytically active species are generated in situ by hydrogenation of a mixture of the cationic diolefin complex $\left[\mathrm{Rh}(\operatorname{cod})_{2}\right] \mathrm{BF}_{4}$ and the biphosphine in dichloromethane. Heller et al. have shown that the solvent in which this hydrogenation is carried out is crucial in determining the catalytically active species that are formed and their reactivity ${ }^{[22]}$ Given this, we decided to test the reaction with the catalytically active species generated in methanol. To our delight, vinylcyclopropane 6 was obtained in a much improved $63 \%$ yield and with a $74 \%$ ee (entry 4, Table 2). Other biphosphine ligands were then evaluated. Whereas DTBM-SegPhos provided the product with a lower yield and lower enantioselectivity (entry 5 , Table 2 ), $\mathrm{H}_{8}$-BINAP was selective but less active in the cascade transformation developed (entry 6, Table 2). Finally, a reaction was run in which methanol was used as the solvent both in the activation of the catalyst and the cyclization. This reaction gave vinylcyclopropane 6 in a 73\% yield in just $1.5 \mathrm{~h}$ reaction time, but the enantioselectivity was considerably reduced (entry 7 , Table 2 ). Best results are thus obtained by activating the catalyst in methanol whilst performing the reaction in DCE (entry 4, Table 2). These optimized conditions were tested in the reaction of selected substrates $\mathbf{1}$, but the reactions were not improved.

Scheme 4 outlines the proposed catalytic cycle. The formation of the catalytic species from the cationic rhodium complex and the $(S)$-BINAP mixture pre- 
Table 2. Optimization of the cyclization of 5. $^{[a]}$

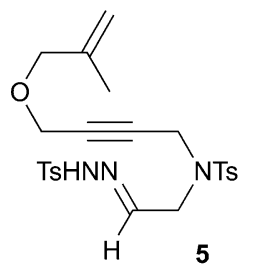

$\left[\mathrm{Rh}(\mathrm{cod})_{2}\right] \mathrm{BF}_{4}(10 \mathrm{~mol} \%)$

phosphine (10 mol\%)

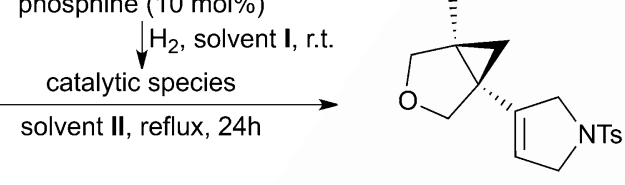

6

\begin{tabular}{llllll}
\hline Entry & Solvent I & Phosphine & Solvent II & Yield [\%] & $e e[\%]$ \\
\hline 1 & $\mathrm{DCM}$ & $(S)$-BINAP & DCE & 29 & 71 \\
$2^{[\mathrm{b}]}$ & $\mathrm{DCM}$ & $(S)$-BINAP & DCE & $1,2-\mathrm{DCP}$ & 14 \\
3 & $\mathrm{DCM}$ & $(S)$-BINAP & DCE & 63 & 53 \\
4 & $\mathrm{CH}_{3} \mathrm{OH}$ & $(S)$-BINAP & DCE & 37 & 74 \\
5 & $\mathrm{CH}_{3} \mathrm{OH}$ & $(R)$-DTBM-SegPhos & DCE & 37 & 23 \\
6 & $\mathrm{CH}_{3} \mathrm{OH}$ & $(R)$-DTBM-SegPhos & $\mathrm{CH}_{3} \mathrm{OH}$ & 73 & 23 \\
$7^{[\mathrm{cc}]}$ & $\mathrm{CH}_{3} \mathrm{OH}$ & $(S)$-BINAP & 46 \\
\hline
\end{tabular}

[a] The reaction was performed with $0.10 \mathrm{mmol}$ of substrate $\mathbf{5}$ in solvent $\mathbf{I I}(1.5 \mathrm{~mL}, 0.067 \mathrm{M})$. The mixture of $\left[\mathrm{Rh}_{\left.(\mathrm{cod}))_{2}\right] \mathrm{BF}}\right.$ and $(S)$-BINAP was treated with hydrogen in solvent $\mathbf{I}$ solution for catalyst activation prior to the reaction.

[b] Reaction run with $\mathrm{K}_{2} \mathrm{CO}_{3}$ (3 equiv.).

[c] The reaction was run for $1 \mathrm{~h} 30 \mathrm{~min}$.

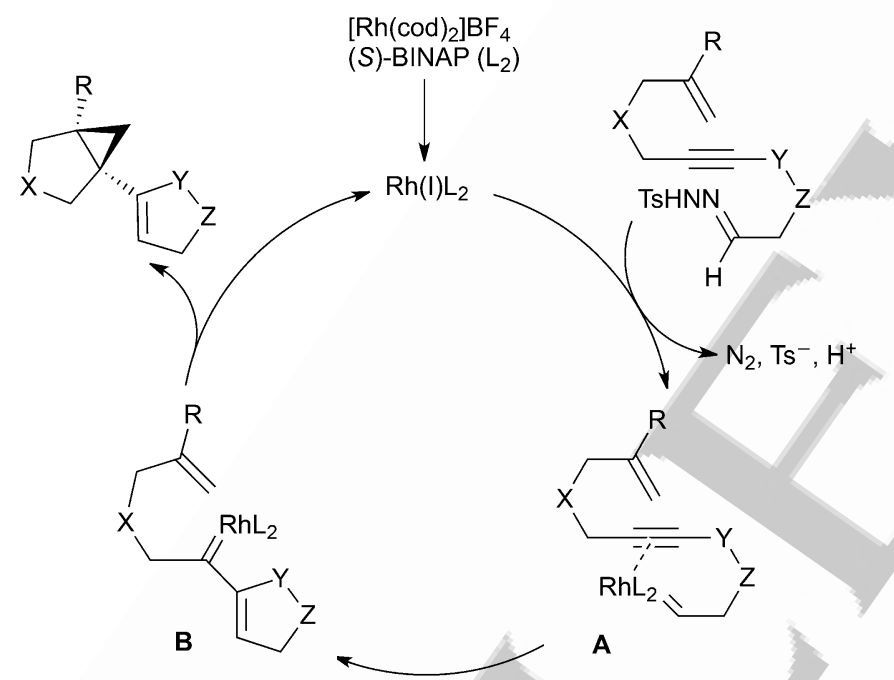

\section{Experimental Section}

Scheme 4. Postulated mechanism.

\section{Cyclization Reaction of 1a; Typical Procedure}

$\left[\mathrm{Rh}(\mathrm{COD})_{2}\right] \mathrm{BF}_{4} \quad(0.0112 \mathrm{~g}, \quad 0.028 \mathrm{mmol})$ and $(S)$-BINAP $(0.0172 \mathrm{~g}, 0.028 \mathrm{mmol})$ were dissolved in $\mathrm{CH}_{2} \mathrm{Cl}_{2}(4 \mathrm{~mL})$ under $\mathrm{N}_{2}$. Hydrogen gas was bubbled to the stirred catalyst solution for 30 minutes and the resulting mixture was concentrated to dryness. The mixture was then dissolved in 1,2dichloroethane $(1.5 \mathrm{~mL})$ and a solution of $\mathbf{1 a}(0.1092 \mathrm{~g}$, $0.28 \mathrm{mmol})$ in 1,2 -dichloroethane $(1.5 \mathrm{~mL})$ was added. The reaction mixture was heated at reflux for 1.5 hours (TLC monitoring). The solvent was evaporated and the residue was purified by column chromatography on silica gel (hexane/ethyl acetate, 10:0 to 9:1) to afford 2a as a colourless solid; yield: $0.0599 \mathrm{~g}(71 \%), 78 \%$ ee.

cedes the formation of the rhodium carbene $\mathbf{A} \cdot{ }^{[23]}$ The rhodium carbene then reacts with the alkyne in a carbene/alkyne metathesis process to afford the rhodium vinyl carbene $\mathbf{B}$ that intramolecularly cyclopropanates the tethered alkene in an enantioselective manner to furnish the chiral vinylcyclopropane and recover the catalytic species.

In summary, we have demonstrated that a chiral cationic rhodium(I) catalytic system enables the enantioselective synthesis of vinylcyclopropanes through a base-free formation of the rhodium carbene and a carbene/alkyne metathesis-cyclopropanation sequence. Thus, non-stabilized rhodium carbenes are capable of mediating this efficient formation of bicyclic cyclopropane-containing scaffolds.

\section{Acknowledgements}

We are grateful for the financial support by the Spanish Ministry of Education and Science (MINECO) (Project CTQ2014-54306-P) and the DIUE of the Generalitat de Catalunya (Project 2014-SGR-931 and FI predoctoral grant to Oे.T.).

\section{References}

[1] D. Y.-K. Chen, R. H. Pouwer, J.-A. Richard, Chem. Soc. Rev. 2012, 41, 4631.

[2] J. A. Monn, M. J. Valli, S. M. Massey, R. A. Wright, C. R. Salhoff, B. G. Johnson, T. Howe, C. A. Alt, G. A. Rhodes, R. L. Robey, K. R. Griffey, J. P. Tizzano, M. J. Kallman, D. R. Helton, D. D. Schoepp, J. Med. Chem. 1997, 40, 528. 
[3] a) L. A. Sorbera, J. Castaner, P. A. Leeson, Drugs Future 2005, 30, 7; b) P. Skolnick, P. Popik, A. Janowsky, B. Beer, A. S. Lippa, Eur. J. Pharmacol. 2003, 461, 99.

[4] M.-L. Liu, Y.-H. Duan, Y.-L. Hou, C. Li, H. Gao, Y. Dai, X.-S. Yao, Org. Lett. 2013, 15, 1000.

[5] X.-F. He, S. Yin, Y.-C. Ji, Z.-S. Su, M.-Y. Geng, J.-M. Yue, J. Nat. Prod. 2010, 73, 45.

[6] O. G. Kulinkovich, in: Cyclopropanes in Organic Synthesis, John Wiley \& Sons, Inc., Hoboken, NJ, 2015.

[7] For reviews, see: a) P. A. Wender, G. G. Gamber, T. J. Williams, Rhodium(I)-catalyzed [5+2], [6+2], and [5+2+1] Cycloadditions: New Reactions for Organic Synthesis, in: Modern Rhodium-Catalyzed Organic Reactions, (Ed.: P. A. Evans), 2005, Wiley-VCH, Weinheim, 2005; b) T. Hudlicky, J. W. Reed, Angew. Chem. 2010, \#\#\#, \#\#\#; Angew. Chem. Int. Ed. 2010, 49, 4864; c) L. Jiao, Z.-X. Yu, J. Org. Chem. 2013, 78, 6842. For selected recent examples, see: d) D. F. Taber, P. Guo, N. Guo, J. Am. Chem. Soc. 2010, 132, 11179; e) D. Garayalde, K. Krüger, C. Nevado, Angew. Chem. 2011, \#\#\#, \#\#\#; Angew. Chem. Int. Ed. 2011, 50, 911; f) M. Laugeois, S. Ponra, V. Ratovelomana-Vidal, V. Michelet, M. R. Vitale, Chem. Commun. 2016, 52, 5332; g) D. Zell, Q. Bu, M. Feldt, L. Ackermann, Angew. Chem. 2016, \#\#, \#\#\#; Angew. Chem. Int. Ed. 2016, 55, 7408; h) T. Mita, H. Tanaka, Y. Higuchi, Y. Sato, Org. Lett. 2016, 18, 2754.

[8] a) H. Lebel, J.-F. Marcoux, C. Molinaro, A. B. Charette, Chem. Rev. 2003, 103, 977; b) H. Pellissier, Tetrahedron 2008, 64, 7041; c) D. M. Hodgson, S. Salik, Curr. Org. Chem. 2016, 20, 4.

[9] a) Z. Zhang, J. Wang, Tetrahedron 2008, 64, 6577; b) M. Jia, S. Ma, Angew. Chem. 2016, \#\#, \#\#\#; Angew. Chem. Int. Ed. 2016, 55, 9134.

[10] For reviews, see: a) H. M. L. Davies, Aldrichimica Acta 1997, 30, 107; b) H. M. L. Davies, Eur. J. Org. Chem. 1999, 2459. For selected recent examples, see: c) L. Deng, A. J. Giessert, O. O. Gerlitz, X. Dai, S. T. Diver, H. M. L. Davies, J. Am. Chem. Soc. 2005, 127, 1342; d) Y. Lian, L. C. Miller, S. Born, R. Sarpong, H. M. L. Davies, J. Am. Chem. Soc. 2010, 132, 12422; e) J. Xu, E. J. E. Caro-Diaz, E. A. Theodorakis, Org. Lett. 2010 12, 3708; f) B. T. Parr, H. M. L. Davies, Angew. Chem. 2013, \#\#\#, \#\#\#; Angew. Chem. Int. Ed. 2013, 52, 10044.

[11] For selected recent references, see: a) D. Benitez, N. D. Shapiro, E. Tkatchouk, Y. Wang, W. A. Goddard III, F. D. Toste, Nat. Chem. 2009, 1, 482; b) F. Miege, C. Meyer, J. Cossy, Org. Lett. 2010, 12, 4144; c) F. Miege, C. Meyer, J. Cossy, Angew. Chem. 2011, \#\#\#, \#\#\#; Angew. Chem. Int. Ed. 2011, 50, 5932; d) F. Miege, C. Meyer, J. Cossy, Chem. Eur. J. 2012, 18, 7810; e) H. Zhang, B. Wang, K. Wang, G. Xie, C. Li, Y. Zhang, J. Wang, Chem. Commun. 2014, 50, 8050.

[12] For selected references, see: a) K. Miki, K. Ohe, S. Uemura, J. Org. Chem. 2003, 68, 8505; b) Y. Harrak, C. Blaszykowski, M. Bernard, K. Cariou, E. Mainetti, V, Mouriès, A.-L. Dhimane, L. Fernsterbank, M. Malacria, J. Am. Chem. Soc. 2004, 126, 8656; c) X. Moreau, J.-P. Goddard, M. Bernard, G. Lemière, J. M. LópezRomero, E. Mainetti, N. Marion, V. Mouriès, S. Thor- imbert, L. Fensterbank, M. Malacria, Adv. Synth. Catal. 2008, 350, 43; d) D. J. Gorin, I. D. G. Watson, F. D. Toste, J. Am. Chem. Soc. 2008, 130, 3736; e) C. A. Sperger, J. E. Tungen, A. Fiksdahl, Eur. J. Org. Chem. 2011, 3719 .

[13] a) M. J. Johansson, D. J. Gorin, S. T. Staben, F. D. Toste, J. Am. Chem. Soc. 2005, 127, 18002; b) I. D. G. Watson, S. Ritter, F. D. Toste, J. Am. Chem. Soc. 2009, 131, 2056.

[14] For a review article, see: a) Ò. Torres, A. Pla-Quintana, Tetrahedron Lett. 2016, 57, 3881; for selected references, see: b) P. Q. Le, J. A. May, J. Am. Chem. Soc. 2015, 137, 12219; c) Y. Shi, V. Gevorgyan, Org. Lett. 2013, 15, 5394; d) R. Yao, G. Rong, B. Yan, L. Qiu, X. Xu, ACS Catal. 2016, 6, 1024; e) X. Wang, Y. Zhou, L. Qiu, R. Yao, Y. Zheng, C. Zhang, X. Bao, X. Xu, Adv. Synth. Catal. 2016, 358, 1571; f) S. Moulin, H. Zhang, S. Raju, C. Bruneau, S. Dérien, Chem. Eur. J. 2013, 19, 3292; g) Y. Ni, J. Montgomery, J. Am. Chem. Soc. 2006, 128, 2609; h) C. González-Rodríguez, J. R. Suárez, J. A. Varela, C. Saá, Angew. Chem. 2015, \#\#\#, \#\#\#; Angew. Chem. Int. Ed. 2015, 54, 2724.

[15] D. F. Harvey, D. M. Sigano, Chem. Rev. 1996, 96, 271.

[16] a) P. F. Korkowski, T. R. Hoye, D. B. Rydberg, J. Am. Chem. Soc. 1988, 110, 2676; b) T. R. Hoye, C. J. Dinsmore, D. S. Johnson, P. F. Korkowski, J. Org. Chem. 1990, 55, 4518; c) A. Padwa, K. E. Krumpe, Y. Gareau, U. Chiacchio, J. Org. Chem. 1991, 56, 2523; d) D. F. Harvey, M. F. Brown, J. Org. Chem. 1992, 57, 5559; e) T. R. Hoye, K. Chen, J. R. Vyvyan, Organometallics 1993, 12, 2806; f) A. Padwa, D. C. Dean, D. J. Fairfax, S. L. Xu, J. Org. Chem. 1993, 58, 4646; g) A. Padwa, M. D. Weingarten, J. Org. Chem. 2000, 65, 3722.

[17] Ò. Torres, T. Parella, M. Solà, A. Roglans, A. Pla-Quintana, Chem. Eur. J. 2015, 21, 16240.

[18] a) D. F. Taber, P. Guo, J. Org. Chem. 2008, 73, 9479; b) J. Barluenga, C. Valdés, Angew. Chem. 2011, \#\#\#, \#\#\#; Angew. Chem. Int. Ed. 2011, 50, 7486; c) Z. Shao, H. Zhang, Chem. Soc. Rev. 2012, 41, 560; d) Q. Xiao, Y. Zhang, J. Wang, Acc. Chem. Res. 2013, 46, 236.

[19] See the Supporting Information for the detailed synthesis of the substrates.

[20] CCDC 1484927 [compound $(1 R, 5 S)$-2a] contains the supplementary crystallographic data for this paper. These data can be obtained free of charge from The Cambridge Crystallographic Data Centre via www.ccdc.cam.ac.uk/data_request/cif. The thermal ellipsoids in the ORTEP plot of the X-ray structure of $(1 R, 5 S)-2 \mathrm{a}$ are drawn at $50 \%$ probability. The crystallized product corresponds to the major enantiomer of the sample as has been confirmed by chiral HPLC analysis.

[21] M. P. Doyle, R. Duffy, M. Ratnikov, L. Zhou, Chem. Rev. 2010, 110, 704.

[22] A. Preetz, C. Fischer, C. Kohrt, H.-J. Drexler, W. Baumann, D. Heller, Organometallics 2011, 30, 5155.

[23] The $p$-methylphenylsulfonyl group is recovered at the end of the reaction as $p$-toluenesulfoxy- $p$-toluenesulfonate. For the characterization of the compound, see: Y.-S. Hong, H.-M. Kim, H.-S. Kim, Y.-T. Park, Bull. Korean Chem. Soc. 1999, 20, 1524. 
6 An Enantioselective Cascade Cyclopropanation Reaction Catalyzed by Rhodium(I): Asymmetric Synthesis of Vinylcyclopropanes

(11) Adv. Synth. Catal. 2016, 358, 1-6

$\square$ Òscar Torres, Anna Roglans, Anna Pla-Quintana*

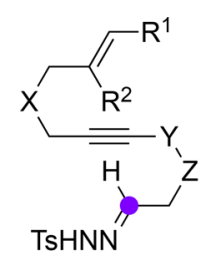

$\left[\mathrm{Rh}(\mathrm{cod})_{2}\right] \mathrm{BF}_{4}(10 \mathrm{~mol} \%)$

(S)-BINAP (10 mol\%)

$\checkmark \mathrm{H}_{2}$, r.t.

catalytic species
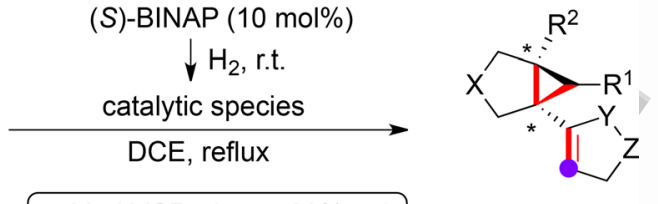

10

- chiral VCPs (up to $89 \%$ ee)

- one-step reaction

- no base needed

- non-stabilized carbenoids 